\title{
Recovery from the 5-AU Induced Blockage in Interphase: Evidence for Differential Recovery
}

\author{
D. Davidson \\ Department of Biology, McMaster University, \\ Hamilton, Ontario, Canada L8S 4K1
}

Received September 12, 1980

Treatment with 5-aminouracil (5-AU) has two effects on proliferating cells: 1) it induces a temporary block at the $\mathrm{S}-\mathrm{G}_{2}$ transition or at the end of $\mathrm{S}$ phase (Diez, Gonzalez-Fernandez and Lopez-Saez 1976, Scheuermann and Klaffke-Lobsien 1973, Socher and Davidson 1971) and 2) it reduces the rate of DNA synthesis (Jakob and Trosko 1965, Scheuermann and Klaffke-Lobsien 1973). The results of treatment are, first, a fall in mitotic index (MI) and, subsequently, partial synchronization of cells entering mitosis (refs. in Davidson, Golding and Armstrong 1979).

The response to 5-AU is as rapid in root primordia of $V$. faba as in primary roots and fully emerged laterals. This shows that: 1) there is no barrier to the movement of 5-AU through the root cortex and into the primordia (Rudolph and Davidson 1975 , Socher and Davidson 1971);2) the initial response to 5-AU is the same in all meristems of a root system. The rate of recovery from 5-AU, however, as shown by the re-establishment of mitotic activity, is faster in primordia than in primary or lateral roots (Rudolph and Davidson 1975); it is also faster in some cells of a meristem than in other cells (Clowes 1965, Mattingly 1966).

One problem in analysing the overall response to 5-AU, i. e., both inhibition and recovery, is that meristems are asynchronous; their cells are distributed throughout $\mathrm{G}_{1}, \mathrm{~S}, \mathrm{G}_{2}$ and mitosis. Thus, it is difficult to estimate the extent of the inhibition imposed by $5-\mathrm{AU}$ on cells at different stages of interphase because, in normal meristems, cells in these stages cannot be identified. Because of this difficulty we cannot estimate the number of cycles completed by a cell in the presence of 5-AU. One approach to these problems is to follow the behaviour of a marked subpopulation of cells. Mattingly (1966) induced tetraploid cell formation, with colchicine, treated with 5-AU and showed that the tetraploid cells underwent a complete cell cycle in the presence of 5-AU. Furthermore, these tetraploid cells entered mitosis at the same time as the first diploid cells to recover from the 5-AU blockade.

The sensitivity of $\mathrm{G}_{1}$ cells to 5-AU has been studied here by treating with colchicine, to induce tetraploid cells, and then treating these cells for two hours during $\mathrm{G}_{1}$ with 5-AU. Other root systems were treated with colchicine and then with 5-AU for up to 26 hours. Recovery from 5-AU treatment occurred more rapidly in primordia than in primary roots or fully emerged lateral roots, even with a continuous exposure to 5-AU. These results, reported here, suggest that the ability to overcome the block imposed by 5 -AU is achieved by whole meristems, not merely by individual cells acting independently. In turn, this suggests a change in the physiological state of a meristem that involves cell-cell interations. This conclusion is largely 
based on the speed of recovery of polyploid cells. Since it could be that colchicine was stimulating cells blocked by 5-AU, roots were treated with colchicine after an 18 hour exposure to 5-AU. It was found that colchicine did not increase the speed of recovery from 5-AU. Thus, the recovery of polyploid cells serves as a valid indicator of overall recovery within a meristem.

\section{Materials and methods}

Beans, Vicia faba, were grown as previously described (Rudolph and Davidson 1975). When lateral roots were $2 \mathrm{~cm}$ long whole root systems were treated in one of the following ways:

1. $0.025 \%$ colchicine for 2 hours and fixed 13 to 17 hours from the start of the colchicine treatment.

2. $0.025 \%$ colchicine for 2 hours, $350 \mathrm{ppm} 5$-AU for 2 hours and fixed 13 to 17 hours from the start of the colchicine treatment.

3. 5-AU for 2 hours, allowed to recover for 1 hour and then fixed.

4. $0.025 \%$ colchicine for 2 hours and then replaced in water or grown in 5-AU for 22 to 26 hours.

5. 5-AU for 22 to 26 hours.

6. 5-AU for 18 hours and then treated with colchicine for 3 hours and fixed 3,6 , 9 or 12 hours later.

7. 5-AU for 18 hours and then fixed at $6,9,12$ or 15 hours.

Untreated roots were fixed at appropriate times.

Whole root system swere fixed in the standard way and squash preparations were made after hydrolysis and staining in Feulgen's reagent (Rudolph and Davidson 1975). Preparations were made of meristems of primary and lateral roots and of primordia. Except in the case of small primordia, 5000 cells were scored from preparations of each type of meristem, 1000 cells from each of 5 slides. Mean mitotic index (MI $\pm \mathrm{SD}$ ) was determined. The frequencies of diploid, tetraploid, or polyploid cells were determined and are given as mean number $\pm S D$ per 1000 cells.

Roots from treatments 6 and 7 were not squashed; cells were dissected out, stained with Feulgen's reagent and Fast Green (Bansal and Davidson, 1978) and nuclear volumes were determined (White and Davidson 1976).

\section{Results}

\section{Colchicine 2 hours and 5-AU 2 hours}

The first mitotic cells in which colchicine suppresses anaphase begin to form tetraploid nuclei about 2 hours after the beginning of treatment. By treating with 5-AU immediately after colchicine the tetraploid cells were exposed to 5-AU for the first 2 hours of $G_{1}$. The effect of 5-AU on this early part of interphase was determined by measuring the time the tetraploid cells take to reach mitosis.

In lateral roots (Table 1) treated only with colchicine there were $18.0 \pm 3.7$ tetraploid mitoses per 1000 cells 13 hours after the beginning of treatment and $37.0 \pm$ 7.0 by 15 hours. In roots treated with colchicine and 5-AU their frequencies were 
$0.6 \pm 0.9$ at 13 hours and $28.0 \pm 4.0$ at 15 hours. This increased to $36.2 \pm 7.4$ by 16 hours. Thus, 5-AU delayed the tetraploid cells with the shortest cell cycles, i. e. those in division by 13 hours, but by 15 to 17 hours the delay was $\sim 1$ hour (Table 1). This may represent a short residual effect on the tetraploid cells when they enter the $\mathrm{S}$ phase.

A similar response was seen in primary roots (Table 2). The first tetraploid mitoses were found in 5-AU treated roots 1 hour after they were seen in roots treated only with colchicine. Similar frequencies of tetraploid mitoses occurred, after the two treatments, about 2 hours apart (Table 2). As in lateral roots, 5-AU has delayed

Table 1. Mean number $\pm \mathrm{SD}$ of tetraploid cells in mitosis in lateral roots of $V$. faba.

Roots were treated with colchicine for 2 hours; some roots were

then treated with 5-AU for 2 hours. Mean $M I \pm S D$, based on all

mitotic cells, i.e., $2 n$ and $4 \mathrm{n}$, is also given. Each mean based on

1000 cells scored from each of 5 roots. Roots were fixed 13 to

17 hours from the start of the colchicine treatment

\begin{tabular}{cccccc}
\hline \multirow{2}{*}{$\begin{array}{c}\text { Hours from } \\
\text { start of } \\
\text { treatment }\end{array}$} & $\begin{array}{c}\text { Cn mitoses } \\
\text { per 1000 cells }\end{array}$ & MI & & \multicolumn{2}{c}{ Colchicine+5-AU } \\
\cline { 2 - 3 } \cline { 5 - 6 } per 1000 cells & MI \\
13 & $18.0 \pm 3.7$ & $24.6 \pm 1.6$ & & $0.6 \pm 0.9$ & $20.8 \pm 2.2$ \\
14 & $22.0 \pm 4.5$ & $19.8 \pm 1.8$ & & $1.4 \pm 0.5$ & $22.6 \pm 1.9$ \\
15 & $37.0 \pm 7.0$ & $17.8 \pm 1.3$ & & $28.2 \pm 4.0$ & $35.6 \pm 1.6$ \\
16 & $52.4 \pm 6.6$ & $14.4 \pm 3.3$ & & $36.2 \pm 7.4$ & $39.5 \pm 2.7$ \\
17 & $59.7 \pm 7.3$ & $11.3 \pm 3.1$ & & $53.4 \pm 6.3$ & $28.8 \pm 2.4$ \\
\hline
\end{tabular}

Table 2. Mean number \pm SD tetraploid cells in mitosis in primary roots of $V$. faba.

Roots were treated and scored as described for the lateral roots of Table 1

\begin{tabular}{cccccc}
\hline $\begin{array}{c}\text { Hours from } \\
\text { start of } \\
\text { treatmemt }\end{array}$ & \multicolumn{2}{c}{ Colchicine } & & \multicolumn{2}{c}{ Colchicine+5-AU } \\
\cline { 2 - 3 } \cline { 5 - 6 } & per 1000 cells & MI & & $\begin{array}{c}\text { 4n mitoses } \\
\text { per 1000 cells }\end{array}$ & MI \\
\hline 13 & 0 & $26.6 \pm 1.1$ & & 0 & $12.9 \pm 1.3$ \\
14 & $6 \pm 1.9$ & $22.9 \pm 0.9$ & & 0 & $14.2 \pm 1.3$ \\
15 & $13.4 \pm 3.9$ & $23.5 \pm 1.1$ & & $0.6 \pm 0.9$ & $37.4 \pm 3.1$ \\
16 & $35.6 \pm 9.8$ & $22.3 \pm 1.9$ & & $2.2 \pm 0.8$ & $28.8 \pm 8.3$ \\
17 & $46.2 \pm 8.6$ & $19.4 \pm 2.1$ & & $13 \pm 2.2$ & $29.6 \pm 4.5$ \\
\hline
\end{tabular}

the progress of tetraploid cells to mitosis, but only by 1 to 2 hours. This effect is in sharp contrast with that on cells at later stages in the cell cycle.

The relatively small effect of 5-AU on cell cycle duration of the marked subpopulation of tetraploid cells is not due to a general failure of a 2 hour treatment with 5-AU to delay progress through the cell cycle. In lateral roots, for example, the M. I. of untreated roots was $8.1 \pm 1.4$; this had fallen to $4.9 \pm 0.71$ hour after the end of the 2 hour treatment with 5-AU. It has also been shown that at later hours M. I. continues to decrease following a 2 or 3 hour treatment with 5-AU (Jakob and Trosko 1965. Rudolph and Davidson 1975). Further evidence that a 2 hour treatment with 5-AU was effective is the mitotic synchrony seen in both 
primary and lateral roots; M. I. reaches 37.4 in primary roots (Table 2) and 39.5 in lateral roots (Table 1 ).

To induce the mitotic synchrony seen 9 to 13 hours after the end of treatment 5-AU must continue to block cells long after the roots were removed from the 5-AU solution. A significant proportion of the diploid cells in $S$ or $\mathbf{G}_{1}$ during treatment must be blocked, or delayed, when they reach the $S-G_{2}$ transition point and their interphase is extended by several hours. But the tetraploid cells, exposed to 5-AU in the first part of their $G_{1}$, were delayed by only 1 to 2 hours. This confirms that $5-\mathrm{AU}$ is not equally effective at all phases of interphase.

Table 3. Mean MI $\pm \mathrm{SD}$ in various meristems of roots of $V$. faba treated continuously with 5 -AU

\begin{tabular}{lccc}
\hline & 22 hours & 24 hours & \multicolumn{1}{c}{ 26 hours } \\
\hline primary & $0.33 \pm 0.03$ & $0.28 \pm 0.01$ & $3.48 \pm 0.43$ \\
lateral & $0.71 \pm 0.12$ & $3.95 \pm 0.6$ & $5.57 \pm 0.53$ \\
just emerged lateral & $4.22 \pm 0.66$ & $8.82 \pm 1.02$ & $10.87 \pm 1.04$ \\
large primordium & $8.22 \pm 1.04$ & $17.37 \pm 2.44$ & $18.87 \pm 1.3$ \\
\hline
\end{tabular}

Table 4. Mean $\mathrm{MI} \pm \mathrm{SD}$ in various meristems of roots of $V$. faba treated with colchicine for 2 hours. Some roots were also treated with 5-AU for 22 hours, beginning immediately after the treatment with colchicine

\begin{tabular}{lcccccccc}
\hline & Primary & Lateral & $\begin{array}{c}\text { Just } \\
\text { emerged } \\
\text { lateral }\end{array}$ & $\begin{array}{c}\text { Just not } \\
\text { emerged }\end{array}$ & $\begin{array}{c}\text { Very large } \\
\text { primor- } \\
\text { dium }\end{array}$ & $\begin{array}{c}\text { Large } \\
\text { primor- } \\
\text { dium }\end{array}$ & $\begin{array}{c}\text { Small } \\
\text { primor- } \\
\text { dium }\end{array}$ \\
\hline $\begin{array}{l}22 \text { hours } \\
\text { colchi- } \\
\text { cine }\end{array}$ & $20.3 \pm 0.8$ & $17.8 \pm 0.9$ & $16.2 \pm 0.6$ & $16.3 \pm 1.8$ & $19.4 \pm 2.2$ & $18.3 \pm 1.2$ & $19.8 \pm 2.8$ \\
$\begin{array}{c}\text { colchin- } \\
\text { cine }+ \\
5-A U\end{array}$ & $0.3 \pm 0.8$ & $1.1 \pm 0.1$ & $3.2 \pm 0.8$ & $8.1 \pm 1.1$ & $20.1 \pm 2.5$ & $21.9 \pm 4.3$ & $27.8 \pm 2.6$ \\
\hline $\begin{array}{l}26 \text { hours } \\
\text { colchi- } \\
\text { cine }\end{array}$ & $22.3 \pm 5.9$ & $17.9 \pm 1.7$ & $15.3 \pm 0.8$ & $19.8 \pm 3.1$ & $19.2 \pm 3.2$ & $17.6 \pm 1.7$ & $22.9 \pm 1.1$ \\
$\begin{array}{c}\text { colchi- } \\
\text { cine }+ \\
5-\mathrm{AU}\end{array}$ & $0.4 \pm 0.6$ & $4.4 \pm 1.2$ & $36.9 \pm 6.6$ & $25.5 \pm 4.9$ & $54.4 \pm 3.5$ & $25.6 \pm 2.5$ & $31.16 \pm 4.8$ \\
\hline
\end{tabular}

2. Colchicine 2 hours and 5-AU 22 to 26 hours

In primary and lateral roots, M. I. was low after 22 and 24 hours treatment with 5 -AU but cells were entering mitosis by 26 hours (Table 3 ). In meristems of just emerged lateral roots and large primordia recovery had begun by 22 hours and evidence of mitotic synchronization was seen at 26 hours. In all meristems of $V$. faba roots cells are blocked by 5-AU and M. I. falls but primordia recover more rapidly than primary or lateral roots (Table 3 ).

This pattern of response was also seen in roots treated with colchicine and then 5-AU (Table 4). From 22 to 26 hours M. I. increased to a greater extent in primordia and in just emerged roots than in primary or lateral roots. The highest degree of synchronization was seen in very large primordia at 26 hours; M. I. was 
54.4 \pm 3.5. The increased M. I. at $26 \mathrm{cf.} 22$ hours (Table 4) results in part from increases in the number of polyploid cells entering mitosis (Table 5). In roots treated only with colchicine most of the polyploid cells are tetraploid but some octoploid cells were present. These comprised $1-6 \%$ of the polyploid cells at 22 hours and as many as $21 \%$ of the polyploid cells, in large and small primordia, at 26 hours. In roots treated with colchicine and 5-AU only tetraploid cells were seen in division and the increases in the number of polyploid cells between 22 and 26 hours in just emerged roots, just not emerged, very large primordia and large primordia, refer only to tetraploid cells.

At 22 and 26 hours, therefore, a heterogenous mixture of cells had entered mitosis; there were diploid, tetraploid and octoploid cells in roots treated with colchicine and then 5-AU. The octoploid cells provide a useful internal reference; they have divided twice since the beginning of the colchicine treatment, i. e. twice in 24 hours. Therefore, they show that the minimum duration of a cell cycle in polyploid cells is 12 hours; for most of the cells it is 14 hours. The octoploid cells are also useful since they demonstrate that colchicine continued to exert its effect for at

Table 5. Mean number \pm S.D. of polyploid cells per sample of 1000 cells in various meristems of roots of $V$. faba. These values are from the same roots as those used for Table 4. Each mean is based on a total of 5000 cells

\begin{tabular}{lrrrrr}
\hline & \multicolumn{2}{c}{22 hours } & \multicolumn{2}{c}{26 hours } \\
\cline { 2 - 3 } \cline { 5 - 6 } & Colchicine & $\begin{array}{c}\text { Colchicine } \\
+5-\mathrm{AU}\end{array}$ & Colchicine & $\begin{array}{c}\text { Colchicine } \\
+5-\mathrm{AU}\end{array}$ \\
\hline just emerged lateral & $110.0 \pm 10.3$ & $2.25 \pm 0.5$ & $100.0 \pm 17.0$ & $110.3 \pm 22.3$ \\
just not emerged & $119.3 \pm 9.8$ & $12.5 \pm 5.3$ & $106.5 \pm 10.6$ & $97.5 \pm 35.5$ \\
very large primordium & $95.8 \pm 6.5$ & $44.5 \pm 12.2$ & $108.3 \pm 9.9$ & $207.8 \pm 14.9$ \\
large primordium & $141.8 \pm 23.4$ & $51.8 \pm 16.3$ & $110.5 \pm 8.8$ & $103.8 \pm 45.7$ \\
small primordium & $134.7 \pm 8.9$ & $122.9 \pm 12.3$ & $139.2 \pm 15.3$ & $137.3 \pm 6.2$ \\
\hline
\end{tabular}

least 14 hours, i. e. at least till the tetraploid cells were in mitosis. This indicates that the diploid cells seen in mitosis were undergoing their first division since the beginning of the experiment: their cell cycle duration, therefore, has been considerably extended by 5-AU. The response of the tetraploid is somewhat different. They became tetraploid after treatment with colchicine and they complete a whole cycle and enter mitosis at 22 or 26 hours. If their normal cell cycle duration was 14 hours, then 5-AU delayed them by, at most, 8 to 12 hours.

\section{5-AU for 18 hours followed by colchicine}

The cells that are known to have been affected by colchicine are the tetraploids and it may be that they were stimulated by colchicine to overcome the 5-AU imposed block faster than the diploid cells. This possibility was tested by treating roots with 5-AU for 18 hours, then colchicine for 3 hours and measuring the time when cells begin to enter mitosis. The 18 hour treatment reduced M. I. to zero (Table 6) and recovery did not begin for about 9 hours. By then M. I. was 2.2 and it increased to 52 after 15 hours recovery. Colchicine did not affect the rate of recovery; M. I. 
in colchicine treated roots was similar to that in roots treated only with 5-AU (Table 6).

As a further check nuclear volumes and cell areas were determined for cells in prophase 9,12 and 15 hours after the end of 5-AU treatment. It appears that basically the same populations of cells enter division with or without the colchicine treatment (Table 6). This result is evidence that tetraploid cells do not recover faster from the effects of 5-AU because of colchicine; rather it suggests that recovery from the block imposed by 5-AU does not occur independently in individual cells but affects the whole meristem. Diploid and tetraploid cells, present in the same meristem recover together. When recovery begins all cells in the meristem are affected, not just the first cells to have been blocked by 5-AU.

Table 6. M. I., mean \pm S.D. nuclear volume and cell area in primary roots of $V$. faba treated with 5-AU for 18 hours. Some roots were also treated with colchicine for 3 hours. M. I. is based on 2000 cells. Interphase nuclear volumes are based on 300 nuclei. For prophases, nuclear volumes and cell area are based on 150 cells.

The prophases scored were all diploid

\begin{tabular}{|c|c|c|c|}
\hline & $\begin{array}{l}\text { Mean nuclear } \\
\text { volume } \pm \text { S.D. }\end{array}$ & $\begin{array}{l}\text { Mean cell } \\
\text { area } \pm \text { S.D. }\end{array}$ & M.I. \\
\hline \multicolumn{4}{|l|}{ Interphase } \\
\hline Control & $698 \pm 217$ & & 7.8 \\
\hline 5-AU & $1207 \pm 441$ & & 0 \\
\hline $5-\mathrm{AU}+6$ hours & $1390 \pm 415$ & & 0 \\
\hline 5 -AU +3 hours colchicine +3 hours & $1424+382$ & & 0.1 \\
\hline \multicolumn{4}{|l|}{ Prophase } \\
\hline $5-\mathrm{AU}+9$ hours & $2635 \pm 876$ & $896 \pm 234$ & 2.2 \\
\hline $5-\mathrm{AU}+3$ hour colchicine +6 hours & $2599 \pm 806$ & $939 \pm 248$ & 1.4 \\
\hline $5-\mathrm{AU}+12$ hours & $1682 \pm 389$ & $596 \pm 137$ & 5.0 \\
\hline $5-\mathrm{AU}+3$ hours colchicine +9 hours & $1893 \pm 591$ & $684 \pm 172$ & 6.1 \\
\hline $5-\mathrm{AU}+15$ hours & $1873 \pm 613$ & $595 \pm 141$ & 52 \\
\hline 5 - $\mathrm{AU}+3$ hours colchicine +12 hours & $1673 \pm 831$ & $543 \pm 229$ & 46.8 \\
\hline
\end{tabular}

Discussion

5-AU is a potent inhibitor of proliferating cells. It induces a temporary block at about the $S-G_{2}$ transition point, which results in a fall in M. I. Even short treatments, of 2 to 3 hours, reduce M. I. and maintain it at about zero for 10 to 12 hours (Jakob and Trosko 1965, Rudolph and Davidson 1975). In $V$. faba roots, the initial fall in M. I. is due to the 5-AU blockade of fast cycling cells (Socher and Davidson 1970, 1971) and their cell cycle duration is extended by 7 to 9 hours, even by short treatments with 5-AU (Jakob and Trosko 1965, Rudolph and Davidson 1975). Cells exposed to 5-AU during $G_{1}$ however, are delayed by only 1 to 2 hours. The results from a determination of cell cycle duration in tetraploid cells (Tables 1 and 2) show that they were only slightly delayed by 5-AU. Thus in an asynchronous population of cells, such as that of a meristem of $V$. faba, 5-AU arrests cells at the $S-G_{2}$ transition but has little effect on cells in $G_{1}$. By the time the latter cells 
have progressed through $G_{1}$ and $S$ and have reached the $S-G_{2}$ transition, the meristem has almost overcome the block imposed by 5-AU. The result is that the cells blocked by $5-A U$ are recovering and beginning to move through $G_{2}$ at about the same time as the cells treated in $G_{1}$ have caught up with them. When the block is overcome and cells move through $\mathrm{G}_{2}$ and into mitosis, M. I, rises (Tables 1 and 2); both diploid and tetraploid cells divide in synchrony.

A similar pattern of response is seen when roots are treated continuously with 5-AU. The main difference between short and long treatments is the delay before roots begin to recover and show mitotic activity (Tables 1 and 2, compare with Tables 3 and 4). But though recovery of mitotic activity is delayed in roots treated with 5-AU for many hours, roots show a spontaneous recovery even in the presence of 5-AU (Tables 3 and 4, Mattingly 1966). The use of colchicine induced tetraploid cells as markers again shows that by the time cells exposed to 5-AU in $\mathrm{G}_{1}$ have reached the $S-G_{2}$ transition, meristems are beginning to recover. The result is that the duration of the delay is much less in tetraploid cells than in diploid cells, which were already part way through interphase when the 5-AU treatment was initiated. As with the short treatment with 5-AU, the time of entry of tetraploid cells into mitosis coincides with the increase in M. I. (Tables 4 and 5). This is further evidence that the cells that experienced a long delay induced by 5-AU during interphase divide in synchrony with the tetraploid cells that have been delayed for only a few hours.

The mechanism underlying the differential response of diploid and tetraploid cells could involve a stimulation by colchicine. But when roots were treated with 5-AU for 18 hours and then treated with colchicine, no stimulation was found (Table 6). 5-AU had obviously affected the roots: $M$. I. was zero at 18 hours and nuclear volume and cell area had increased (Table 6). Mean volumes of diploid nuclei are similar to those of tetraploid nuclei, after extended treatment with 5-AU (Bansal and Davidson 1978, Davidson, Golding and Armstrong 1979), and the nuclei should be capable of division. Even with their increased size and even though colchicine is able to stimulate interphase cells to complete interphase at above normal rates (Davidson 1979, Webster and Davidson 1969) cells blocked by 5-AU were not induced, by colchicine, to recover from 5-AU at a more rapid rate. It appears, therefore, that some other mechanism must be involved.

An interesting aspect of the response to $5-\mathrm{AU}$ is the pattern of recovery. Whether we compare cell behaviour within a meristem (Tables 1 and 2, Mattingly 1966) or between different meristems (Tables 3-5; Rudolph and Davidson 1975), we find evidence of differential rates of recovery from 5-AU. Thus, some cells show a delay of only a few hours while others are delayed by as much as 24 hours. The onset of recovery from 5-AU simultaneously affects a significant proportion of cells in a meristem and it is this coincident release of many cells from the 5-AU blockade that later results in mitotic synchrony.

The simultaneous recovery of cells throughout the meristem suggests that the whole meristem overcomes the 5-AU block, not just individual cells. This argues for some type of cell-cell interaction. One type of interaction could involve the production and distribution of a diffusible factor that enables cells to recover from 
5-AU. Roots of $V . f a b a$ may make such factors since primordia recover faster than primary or fully emerged lateral roots. Furthermore, it has been shown that deoxyribonucleosides stimulate recovery from the 5-AU blockade (Rudolph and Davidson 1975). It may then be that one result of the disturbance of the flow of cells through the cell cycle is a temporary increase in the pools of pyrimidine nucleosides and this helps cells to overcome the inhibition imposed by 5-AU. A second possibility is that cells are induced to synthesize enzymes that metabolize 5-AU and so reduce the concentration of the inhibitor below an effective level. Whatever the mechanism, it appears to involve response at the tissue level and indicates cellcell interactions.

\section{Summary}

Roots of $V$. faba were treated with 5 -AU (350 ppm) and colchicine $(0.025 \%)$ in various combinations. Tetraploid cells, induced by colchicine, were used as a subpopulation of marked cells with which to study the effect of 5-AU on $\mathrm{G}_{1}$ cells and to determine the relative rates of recovery, from the 5-AU induced block, of cells in different phases of the cell cycle. These aspects were followed in roots given 2,18 or up to 26 hours in 5-AU: colchicine treatments were given either immediately before or after the 5-AU treatment. Cells exposed to 5-AU in the early part of interphase recovered more rapidly than those treated at the $S-G_{2}$ transition. This recovery does not appear to be due to a stimulation of cells by colchicine, since treatments with colchicine after 5-AU did not speed up the recovery of the cells. Recovery appears to be a response of the whole meristem, not just of individual cells. This suggests some form of cell-cell interaction that results in the reversal of the 5-AU blockade.

\section{Acknowledgements}

I am grateful to the National Science and Engineering Research Council of Canada for support (A-5050) and to Ms. G. Long and Ms. E. Pertens for technical help.

\section{References}

Bansal, J. and Davidson, D. 1978. Heterogeneity of meristematic cells of $V$. faba: evidence from nuclear and chromosome volume and from nuclear protein content. Caryologia 31: 161177.

- and - 1978. Analysis of growth of tetraploid nuclei in roots of Vicia faba. Cell Tissue Kinet. 11: 193-200.

Clowes, F. A. L. 1965. Synchronization in a meristem by 5-aminouracil. J. Exp. Bot. 16: 581586.

Davidson, D. 1979. Colchicine stimulation of interphase cells: timing the response using 5-aminouracil. Cytologia 44: 633-638

-, Golding, B. G. and Armstrong, S. W. 1978. Increases in nuclear volume and cell size in meristematic cells arrested by 5-aminouracil. Protoplasma 96: 47-57.

Diez, J. L., Gonzalez-Fernandez, and Lopez-Saez, J. F. 1976. Mechanism of mitotic synchronization induced by 5-aminouracil. Exp. Cell Res. 98: 79-89. 
Jakob, K. M. and Trosko, J. E. 1965. The relation between 5-aminouracil-induced mitotic synchronization and DNA synthesis. Exp. Cell Res. 40: 56-67.

Mattingly, E. 1966. Synchrony of cell division in root meristems following treatment with 5aminouracil. In: Cell Synchrony ed. I. L. Cameron and G. D. Papilla pp. 256-268. Academic Press. New York.

Rudolph, J. M. and Davidson, D. 1975. Mitotic synchrony induced in meristems of Vicia faba by 5-aminouracil: response of synchronized cells to deoxyribonucleosides. New Phytol. 74: $277-286$.

Scheuermann, W. and Klaffke-Lobsien, G. 1973. On the influence of 5-aminouracil on the cell cycle of root tip meristems. Exp. Cell Res. 76: 428-436.

Socher, S. H. and Davidson, D. 1970 . Heterogeneity in $G_{2}$ duration during lateral root development. Chromosoma 31: 478-484.

- and - 1971. 5-aminouracil treatment. A method of estimating $G_{2}$. J. Cell Biol. 48: 248252.

Webster, P.L. and Davidson, D. 1968. Evidence from ${ }^{3} \mathrm{H}-\mathrm{TdR}$ labelled meristems of $V$. faba of two cell populations. J. Cell Biol. 39: 333-338.

- and - 1969. Changes in the duration of the mitotic cycle induced by colchicine and indol3yl-acetic acid in Vicia faba roots. J. Exp. Bot. 20: 671-685.

White, R. L. and Davidson, D. 1976. Growth of pollen grain nuclei of Tradescantia paludosa. Can. J. Genet. Cytol. 18: 385-393. 